\title{
High performance peel grinding of steel shafts using coarse electroplated CBN grinding wheels
}

\author{
B. Denkena ${ }^{1} \cdot$ A. Krödel ${ }^{1} \cdot$ M. Wilckens ${ }^{1}$ (1)
}

Received: 18 January 2021 / Accepted: 12 March 2021 / Published online: 31 March 2021

(c) The Author(s) 2021

\begin{abstract}
Grinding is widely known for its low material removal rates and high surface quality. However, recent developments in production processes for cubic boron nitride (CBN) abrasive grains have led to commercially available grain sizes larger than $300 \mu \mathrm{m}$. These superabrasive CBN-grains allow higher material removal rates during grinding of hardened steel components. Currently, these components are pre-machined with turning processes before hardening and finishing the work piece by grinding. However, the turning process can be eliminated by grinding with coarse CBN-grains since higher depths of cut are achievable when machining hardened components. This paper explores the limits of grinding wheels using grains with a size of B602 during soft and hard machining in comparison to conventional B252 grains. It is shown that the use of coarser grains leads to lower process forces, higher (tensile) residual stress and higher surface roughness. Residual stress and surface roughness are of less importance as these grains are to be used mainly in roughing operations with ensuing finishing operations for the required surface properties. Over all investigations, especially in hard machining, neither grain nor tool wear was observed for the B602 grains, whereas the B252 tool was severely clogged during the experiments. Additionally, the grinding force ratio indicates that the coarse grain tools have not yet reached their productivity limit as it increases over all investigated feeds. This indicates improving tool performance with lower amounts of rubbing for increasing feed rate during hard grinding and shows the potential for the industrial use of higher feed rates with larger grains.
\end{abstract}

Keywords Grinding · High Efficiency Deep Grinding · Roughing $\cdot$ CBN

\section{Introduction}

Increasing demand for quality and efficiency in production technologies creates high pressure to optimize machine tools, tools, and processes. Especially geometrically undefined cutting with its significance for high-precision parts and high-quality surfaces needs to be constantly improved to meet the markets demands $[1,2]$. However, grinding is no longer solely used for finishing operations. High performance grinding with cutting speeds of $\mathrm{v}_{\mathrm{c}}>80 \mathrm{~m} / \mathrm{s}$ and depths of cut of $a_{e}>0.3 \mathrm{~mm}$ instead focuses on high material removal rates [3]. Tawakoli [4] introduced the concept of High Efficiency Deep Grinding (HEDG) as a combination of deep-creep feed grinding with efficient high-rate grinding [5]. Further studies, including the work of Stephenson [6],

M. Wilckens

wilckens@ifw.uni-hannover.de

1 Institute of Production Engineering and Machine Tools, Leibniz Universität Hannover, Hanover, Germany
Morgan [7], and Jin [8] investigated the industrial application of HEDG. The full scope of the processes applicability and its limits is, however, not fully explored.

Grinding with cubic boron nitride wheels continually gains importance for the machining of hardened steels and many investigations focus on increasing the productivity of rough grinding processes. In order to improve the performance of CBN wheels, Aurich and Denkena focus on the patterning of the abrasive layer $[9,10]$. Marschalkowski and Uhlmann work specifically on the tool design [11] and use of electroplated tools [12] for high speed and high performance grinding processes. Ichida investigated the influence of ultrafine-crystalline abrasive grains in comparison to mono- and polycrystalline grains in vitrified CBN wheels on their performance [13].

These investigations show that the productivity for all roughing operations is limited by tool life, which is influenced by the grinding wheels bond and the specifications of the used abrasive grains. The grain size limits the maximum material removal rate by defining the maximum chip 
thickness and chip space [1]. In construction and natural stone mining, diamond grains of up to $d_{g}=800 \mu \mathrm{m}$ in diameter are used in abrasive cutting [14]. Diamond grains are, however, unsuited for the machining of (hardened) steel as the steels iron acts as a catalyst that reduces the temperature for the degeneration of the diamond to graphite and thus enhances grain wear. CBN on the other hand, is chemically inert to steel and therefore suited for the high performance machining of steel. Until recently, the production of CBN grain sizes larger than $300 \mu \mathrm{m}$ was not possible due to limited process control. However, no scientific investigations of their process and wear behaviour have been conducted since their availability. Preliminary investigations at the Institute of Production Engineering and Machine Tools (IFW) of the Leibniz University Hannover have shown the effectiveness and efficiency of roughing processes using coarse CBN grains. First results in the machining of hardened roller bearing rings show material removal rates for grinding that are significantly higher than in turning [15].

The present paper consequently focuses the limits of positively electroplated grinding wheels with CBN grains larger than $d_{g}=300 \mu \mathrm{m}$ when machining (hardened) steel shafts. The material removal rate will be increased by varying feeds in order to determine the process and wear behaviour of these tools for roughing processes.

\section{Experimental setup}

In this paper, coarse CBN grinding wheels with grain sizes B252 and B602 are used to machine soft and hardened 100Cr6 steel shafts with a diameter of $d_{W}=60 \mathrm{~mm}$ and a length of $\mathrm{d}_{\mathrm{W}}=300 \mathrm{~mm}$ on a Schaudt CR41 cylindrical grinding machine with Castrol Variocut G 600 as coolant lubricant (CL). The

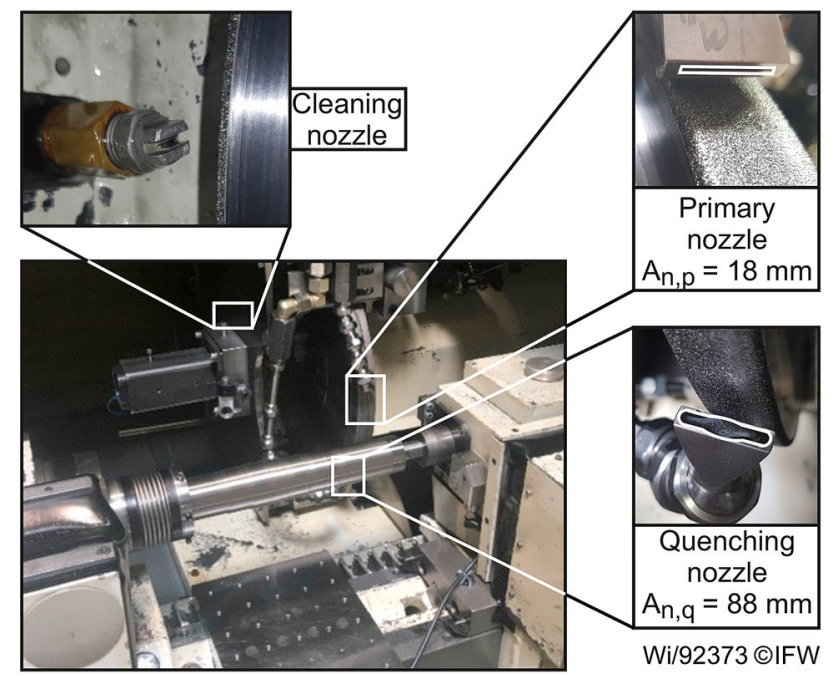

Fig. 1 Experimental setup experimental setup used for this paper is shown in Fig. 1. The shaft is fixed on both sides and driven by the work piece spindle with a maximum rotational speed of $n_{w, \max }=1000 \mathrm{rpm}$ and a maximum torque of $\mathrm{M}_{\mathrm{w}, \max }=48 \mathrm{Nm}$. Process forces are measured by Kistler piezoelectrical dynamometers on both clamping points and averaged. The grinding wheel is driven by the tool spindle, which has a maximum output of $\mathrm{P}_{\mathrm{S}, \max }=43 \mathrm{~kW}$ at a maximum rotational speed of $\mathrm{n}_{\mathrm{S}, \max }=6.000 \mathrm{rpm}$.

To cool and lubricate the process, three coolant nozzles are used simultaneously. A primary nozzle supplies $C L$ in cutting direction with a fluid velocity of $\mathrm{v}_{\mathrm{CL}}=50 \mathrm{~m} / \mathrm{s}$. A quenching nozzle is positioned opposite to it in order to cool the shaft and extinguish potential sparks. Since both nozzles are fed from the same supply, the outlet profile of the nozzles is altered to ensure high velocity on the primary nozzle and a high flow rate on the quenching nozzle as can be seen in Fig. 1 (right). Additionally, a cleaning nozzle is set behind the grinding wheel, which is used to deliver high-pressure CL to clean the grinding tool from adhesions. Over all three nozzles, a cumulative flow of $\mathrm{Q}_{\mathrm{CL}}=130 \mathrm{l} / \mathrm{min}$ is delivered.

The tools for the investigated peel grinding process are $\mathrm{d}_{\mathrm{S}}=440 \mathrm{~mm}$ in diameter and feature a profile with an angled roughing section and a flat section for finishing (Fig. 2). The roughing angle is $\alpha_{r}=12^{\circ}$ in feed direction. Due to this profile, the specific material removal rate is solely dependent on the feedrate, which can be seen in Fig. 2. Increasing the depth of cut $a_{e}$ also increases the width of contact $b_{\text {eff }}$ of the grinding wheel. For additional clarification Eq. 1-3 calculate the specific MRR for peel grinding. It can be seen that the material removal rate per width of active grinding wheel profile $b_{\text {eff }}$ is constant for varying depths of cut $\mathrm{a}_{\mathrm{e}}$.

In order to investigate the chip dimensions for both tools, the machine was cleaned before each experiment and chips were collected from open surfaces within the machine after each experiment. These chips were then measured under a microscope along their most prominent dimension.
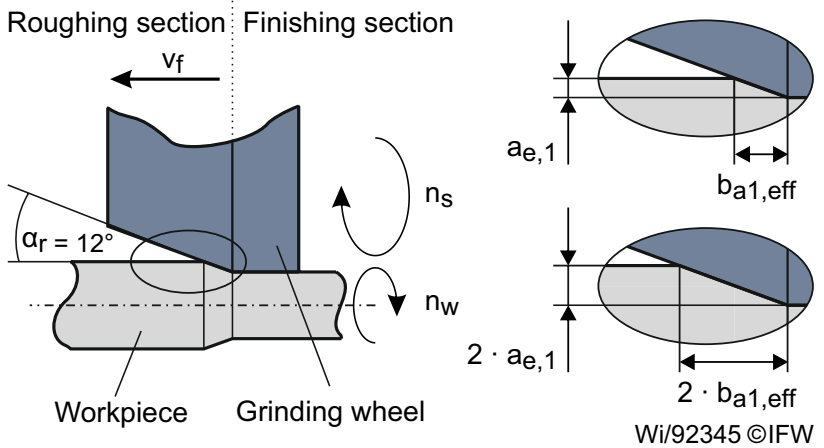

Fig. 2 Tool specification and influence of depth of cut 
Table 1 Experimental plan

\begin{tabular}{ll}
\hline Process parameters & Values \\
\hline Cutting speed $\mathrm{v}_{\mathrm{c}}$ & $100 \mathrm{~m} / \mathrm{s}$ \\
Depth of cut (radial) $\mathrm{a}_{\mathrm{e}}$ & $500 \mu \mathrm{m}$ \\
Speed ratio q & 70 \\
Feed $\mathrm{f}$ & $0.3-1.8 \mathrm{~mm}$ \\
\hline
\end{tabular}

$Q^{\prime}{ }_{w}=\frac{Q_{w}}{b_{e f f}}=\frac{\pi \cdot d_{w} \dot{n}_{w} \cdot \mathrm{f} \cdot \tan \alpha}{60}$

With $Q_{w}=\frac{\pi \cdot d_{w} \cdot n_{w} \cdot \mathrm{f} \cdot a_{e}}{60}$

and $a_{e}=b_{e f f} \cdot \tan \alpha$

This paper focuses on the influence of an increased material removal rate (MRR) on the process behaviour of coarse CBN grains. To increase the MRR, the feed rate is increased. Cutting speed, depth of cut, and cutting speed ratio $\left(q=\mathrm{v}_{\mathrm{s}}\right.$ / $\mathrm{v}_{\mathrm{w}}$ ) have been established during preliminary experiments [11] and are kept constant for all investigations. All fixed and varied process parameters are shown in the experimental plan in Table 1. The listed feeds are investigated in five steps within the listed range. Each experiment was repeated once and the results were averaged.

To ensure constant starting conditions for all investigations, the electroplated grinding wheels are cleaned from adhering material before each experiment. For this purpose, WINTER sharpening stones \#4 with white aluminum oxide are used by hand until all signs of clogging have been removed.

\section{Results and discussion}

\subsection{Process forces and grinding force ratio}

In order to show the differing process behaviour for both grain sizes in soft (left) and hard (right) grinding Fig. 3 shows the measured process normal forces for increasing feeds. According to the state of the art, the number of abrasive grains that engage the workpiece influences the process forces. With increasing numbers of grains throughout the contact area, the process forces are enhanced. This leads to lower process forces for larger abrasive grains as larger grains reduce the number of abrasive grains in the contact area. This is evident in Fig. 3 since lower process forces occur over all investigations with the larger B602 grains compared to the smaller B252 grains. While the process forces are reduced by a growing number of
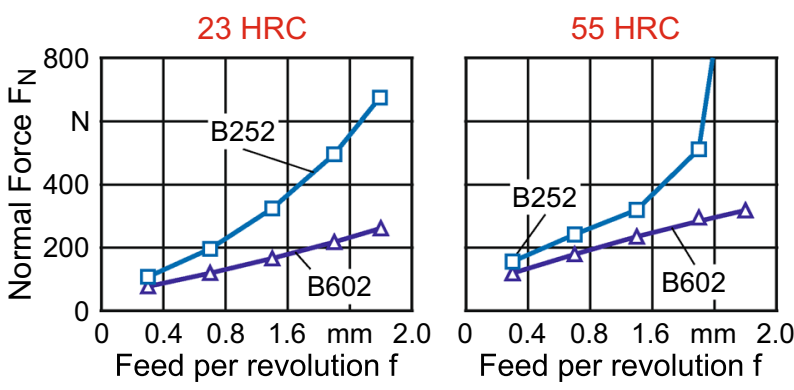

\begin{tabular}{lll}
\hline Process & Grinding tool & Cooling \\
parameters & B252, B602 & Castrol \\
$\mathrm{v}_{\mathrm{C}}=100 \mathrm{~m} / \mathrm{s}$ & Bond: electroplated & Variocut G 600 \\
$\mathrm{q}=70$ & Workpiece & Three coolant \\
$\mathrm{f}=0.3-1.8 \mathrm{~mm}$ & 100Cr6, HRC 23/55 nozzles \\
$\mathrm{a}_{\mathrm{e}}=500 \mu \mathrm{m}$ & & Wi/92375 @IFW
\end{tabular}

Fig. 3 Normal forces for soft and hard grinding with different grain sizes

engaged grains, the load on a single grain is increased. Additionally, when machining soft shafts, the exponential incline of the normal forces over the investigated feeds for the B252 tool also indicates clogging over the course of the investigations. Due to the smaller chip space of this tool and the comparatively large chip thickness, chips get wedged in the chip space and cannot be removed by the cleaning nozzle. This beginning material adhesion hinders the chip removal further and leads to increasing amounts of rubbing in the contact area, which leads to higher normal forces and continuously increasing clogging of the tool. The B602 tool offers more chip space and consequently does not show the same force development. The forces increase linearly by about $45 \mathrm{~N}$ per $0.3 \mathrm{~mm}$ feed increase, indicating no clogging and unchanged sharp grains.

In hard machining the forces progress similarly. The normal forces for the B252 tool increase exponentially due to growing material adhesion and the clogging up of the chip space. However, hardened material forms smaller chips than soft material according to the state of the art. This occurs due to the more brittle material behaviour of hardened steels, which subsequently leads to shorter chips. The clogging of the B252 tool in soft and hard grinding indicates an overload of the available chip space. This may be linked to high process temperatures due to the high MRR and causes softening of the material. Therefore, material adhesion is more likely. Additionally, the progressing clogging of the tool reduces the amount of coolant lubricant in the contact area and thereby the cooling efficiency. Since the chip space of the B252 tool is just about half as large as for the B602 tool, the overload of the chip space and the reduced coolant supply leads to the exponential increase in process forces seen in Fig. 3. 

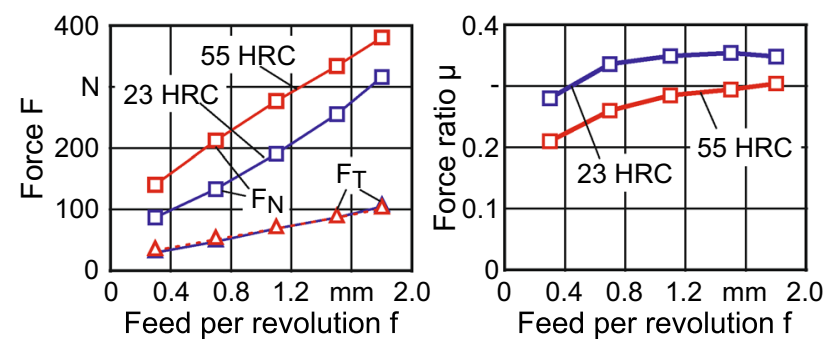

\begin{tabular}{lll}
\hline Process & Grinding tool & Cooling \\
parameters & B602 & Castrol \\
$\mathrm{v}_{\mathrm{C}}=100 \mathrm{~m} / \mathrm{s}$ & Bond: electroplated & Variocut G 600 \\
$\mathrm{q}=70$ & Workpiece & Three coolant \\
$\mathrm{f}=0.3-1.8 \mathrm{~mm}$ & 100Cr6, HRC 23/55 nozzles \\
$\mathrm{a}_{\mathrm{e}}=500 \mu \mathrm{m}$ & & Wi/92376 @IFW
\end{tabular}

Fig. 4 Process forces and grinding force ratio for soft and hard grinding with $\mathrm{B} 602$ grains

The process forces of the $\mathrm{B} 602$ tool rise linearly by about $50 \mathrm{~N}$ per $0.3 \mathrm{~mm}$ feed increase. This increase is slightly higher by $5 \mathrm{~N}$ per $0.3 \mathrm{~mm}$ feed compared to soft machining due to the higher grain load when machining hardened steel. A more detailed analysis of the tools wear behaviour is discussed in chapter 3.2.

In order to further compare soft and hard grinding, the process forces for both processes using the $\mathrm{B} 602$ grinding wheel are presented in Fig. 4 (left). Here, it becomes evident that the normal forces are higher by an average of $58 \mathrm{~N}$ in hard machining, while the tangential and axial forces are within a $5 \mathrm{~N}$ range of each other. Due to the high material removal rate in this roughing operation, the process temperature is very high, which can be seen in large amounts of sparks during the process. Jin $[8,16]$ has shown that the temperature of the contact area in High Efficiency Deep Grinding increases up to the melting point of the machined material. As the material softens up to this point, the initial hardness of the material decreases regarding its influence on the chip formation.

The grinding force ratio (GFR) $\mu=F_{T} / F_{N}$ presented on the right of Fig. 4, sets both normal and tangential forces into relation. It is an indication of a tools overall performance. A high GFR indicates an efficient material removal process with sharp grains and small amounts of friction between grains and work piece. It becomes obvious that the B602 grains are at their performance limit at $\mathrm{f}>1.5 \mathrm{~mm}$ in soft machining as the GFR declines with higher feed rates. This indicates that the tool begins to clog or the grains begin to dull. This can also be seen by the slight exponential increase in normal process forces of the soft grinding (Fig. 4, left) whereas the forces in hard grinding increase linearly. Consequently, the presented GFR for hard grinding increases over all feeds without stagnation, indicating the potential for higher feeds. The increasing GFR shows the growing efficiency of the material removal at higher feeds. While the material removal is more efficient in soft grinding over the investigated feeds, the growth rate of the GFR is higher for higher feeds in hard grinding, verifying clogging-up and thereby reducing the cutting efficiency in soft grinding. The ever increasing GFR at high feeds shows the efficiency of the hard grinding in comparison to the soft grinding. Brittle material removal leads to less material adhesion to the grains, preserving sharp grains in higher feeds. The overall level of the GFR is lower in hard machining because the increased hardness of the shaft leads to higher normal forces. As the material's Rockwell hardness is measured by indentation it is a measure of the normal force needed to bring the abrasive grains of the grinding wheel to their working depth. Therefore, the normal forces in hard grinding is higher than in soft grinding, which, for constant tangential forces, leads to a lower level of the GFR. In conclusion, the coarser B602 grains are well suited for rough grinding operations in soft and hard machining, while the finer B252 grains are unsuited for the presented processes.

\subsection{Wear behaviour}

Electroplated tools consist of only one layer of abrasive grains within a Nickel matrix. Due to the high grain retention forces of this bond, the grains can protrude about 50\% of their diameter from the bond, leaving large chip spaces in between. A single layer of grains also means that these tools cannot be dressed. If the grains dull or break or if the chip space is clogged, the tool can no longer be used. Therefore, it is crucial to investigate the wear behaviour of these tools. Microscopic pictures from a Keyence VHX600 digital microscope in Fig. 5 show the tools initial state at the top and the worn state at the bottom after a removed volume of

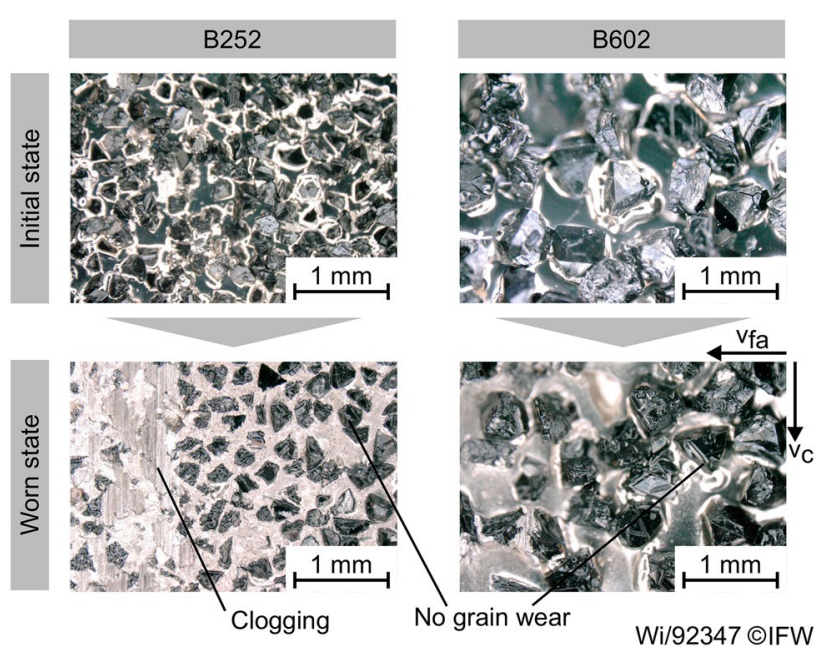

Fig. 5 Initial and worn state of electroplated grinding wheels 
$\mathrm{V}=18.500 \mathrm{~mm}^{3}$ which equals one pass of hard grinding for the electroplated tools with grain sizes B252 and B602 in comparison. The material was removed with a depth of cut of $a_{e}=0.5 \mathrm{~mm}$ and a feed of $\mathrm{f}=1.8 \mathrm{~mm}$ over a length of $1=200 \mathrm{~mm}$. As described before, the B252 tool shows severe clogging to a point where the grain protrusion is eliminated. This leads to rubbing of the clogged material on the work piece, resulting in high process normal forces and temperatures. This explains the exponential incline in process forces for this tool. For the larger grain size B602 (Fig. 5, right) this effect cannot be observed as there is only little material adhesion. After cleaning the clogging from the tools with sharpening stones, the CBN grains themselves on both tools were not visibly worn.

The clogging of the B252 tool can be traced back to the fact that this tool provides an average chip space of about $126 \mu \mathrm{m}$ while the B602 tool provides $301 \mu \mathrm{m}$ that equals the grain protrusion of about $50 \%$ of the grain size. Consequently, chips get wedged between grains more easily and cannot be removed from the contact area as effectively when the grain protrusion is lower. Additionally, the smaller chip space leads to a lower coolant supply into the contact zone, which impedes the removal of chips and thus leads to increased process temperatures.

The chip space and its dimensions provide space for forming chips within the tools topography. Therefore, not only the chip space but also the chip dimensions need to be considered for the tools' wear behavior. If the chips are larger than the provided chip space, they adhere to the tool easily.

The normal chip length distribution is shown in Fig. 6 for the B252 tool on the left and for the B602 tool on the right. For both grain sizes, chips from soft and hard machining were measured under a digital microscope Keyence VHX

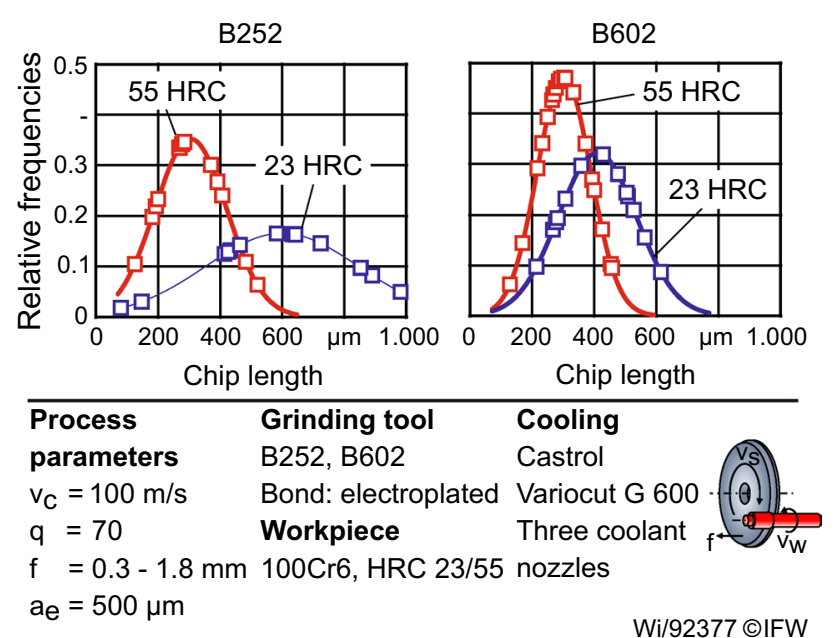

Fig. 6 Normal chip length distribution for B252 and B602 in soft and hard grinding
5000 and depicted accordingly. Due to the ductility of the soft shafts, the chips do not break as easily and longer chips result from the process. This can be seen for both grain sizes, as the chips are longer in soft machining compared to hard machining. This effect is particularly prominent for the B252 tool. The average chip size halfes from $1_{\text {chip }}=593 \mu \mathrm{m}$ in soft machining to $1_{\text {chip }}=302 \mu \mathrm{m}$ in hard machining for the same process parameters. With the $\mathrm{B} 602$ tool the average chip size decreases by $25 \%$ from $1_{\text {chip }}=405 \mu \mathrm{m}$ (soft machining) to $1_{\text {chip }}=299 \mu \mathrm{m}$ (hard machining). With the assumption, that every grain provides one main cutting edge at its center, the cutting edges on electroplated tools are roughly a grain size apart which was verified by measurements of the grain distances on microscopic images. This means that the chips on the B252 tool are longer than the distance between cutting edges and therefore larger than the chip space in between grains. This leads to the clogging of the tool whereas if chips are shorter than the distance between grains, as for the the B602 tool, no clogging occurs.

Another visible effect is that the standard deviation for both tools is lower for hard grinding than for soft grinding. The standard deviation is a measure of how widely a parameter varies. Therefore, a small standard deviation is recognizable in a narrow graph for the normal distribution. In case of the B252 tool the standard deviation $\mathrm{s}_{\mathrm{B} 252, \mathrm{~s}}=243 \mu \mathrm{m}$ halves in hard machining to $\mathrm{s}_{\mathrm{B} 252, \mathrm{~h}}=115 \mu \mathrm{m}$. For the B602 tool it only decreases by about $43 \%$ from $\mathrm{s}_{\mathrm{B} 602, \mathrm{~s}}=122 \mu \mathrm{m}$ to $\mathrm{s}_{\mathrm{B} 602, \mathrm{~h}}=86 \mu \mathrm{m}$. This shows that the investigated chip lengths vary more widely for the smaller grains. This can be accredited to the fact, that one chip might be cut by more than one grain or will get compressed into the available chip space, while other chips expand in between grains.

Thus, it can be summarized that the wear behaviour of the B252 tool is already at its maximum capacity. The increasing clogging of the chip space reduces the number of sharp grains, the amount of coolant supply and the chip removal out of the contact zone. This leads to less effective material removal, increasing process forces and temperatures. The chip length, which is larger than the distance between grains, further increases these effects by closing the chip space. In order to increase the performance of the B252 tool, the chip formation needs to be improved according to the tools available chip space.

As the B602 tool shows no signs of tool wear yet, the grinding wheels performance is not limited over the presented feeds. Conclusively, this tool can be used at even higher feeds to increase its performance.

\subsection{Residual stress}

In order to analyse the thermal and mechanical load on the work piece, the residual stress (RS) was measured on all ground shafts. All measurements were made once as 

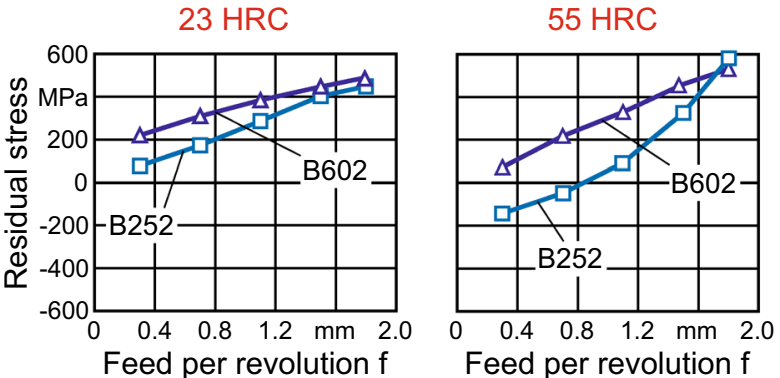

\begin{tabular}{lll}
\hline Process & Grinding tool & Cooling \\
parameters & B252, B602 & Castrol \\
$\mathrm{v}_{\mathrm{C}}=100 \mathrm{~m} / \mathrm{s}$ & Bond: electroplated & Variocut G 600 \\
$\mathrm{q}=70$ & Workpiece & three coolant \\
$\mathrm{f}=0.3-1.8 \mathrm{~mm}$ & 100Cr6, HRC 23/55 nozzles \\
$\mathrm{a}_{\mathrm{e}}=500 \mu \mathrm{m}$ & & Wi/92378 @IFW
\end{tabular}

Fig. 7 Residual stress after peel grinding with varying feeds for soft and hardened shafts

the measurement accuracy was proven to be $\pm 20 \mathrm{MPa}$. The penetration depth on the surface of the shafts was $\tau_{\max }=5.5 \mu \mathrm{m}$ in axial and peripheral direction in accordance to DIN EN 1305. For clarity Fig. 7 only presents the RS in the peripheral direction. The axial RS for all investigations behave similarly on a slightly lower level.

Most investigated feeds induce tensile residual stress, as the graphs in Fig. 7 show. For feeds of $\mathrm{f}=0.3 \mathrm{~mm}$ and $\mathrm{f}=0.7 \mathrm{~mm}$ residual compressive stress was detected. These stresses result from the thermomechanical load during the process. While high process forces induce residual compressive stress, high process temperatures lead to tensile residual stress. Figure 7 shows increasing residual stress for rising feeds for both grain sizes during soft and hard machining. This increase per feed is most significant for the B252 tools as the clogging of the tools leads to large amounts of friction on the work piece surface, which results in rising temperatures in the contact area. On the other hand, the machining with the B602 tool leads to higher total values of residual stress for all investigated feeds. As the resulting RS can be understood as a ratio between process forces and contact area temperature, high residual stress is induced by high temperatures or low normal forces if the other variable remains constant. Since the process forces are lower for the coarser grains, the mechanical load on the work piece surface is reduced, which explains the higher level of residual stress.

In conclusion, the measured residual stress is a result from the process forces and temperature. As the hardened material leads to higher normal process forces over all investigations for both tools, the level of residual stress is lower. The clogging of the B252 tool leads to increasing
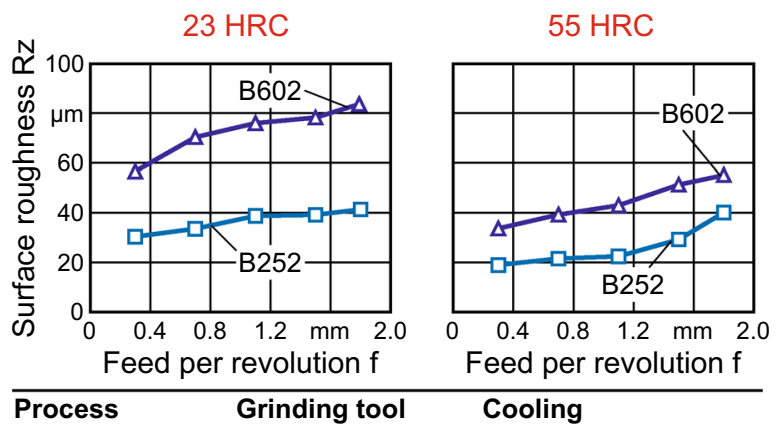

\begin{tabular}{lll}
\hline Process & Grinding tool & Cooling \\
parameters & B252, B602 & Castrol \\
$\mathrm{v}_{\mathrm{C}}=100 \mathrm{~m} / \mathrm{s}$ & Bond: electroplated & Variocut G 600 \\
$\mathrm{q}=70$ & Workpiece & three coolant \\
$\mathrm{f}=0.3-1.8 \mathrm{~mm}$ & 100Cr6, HRC 23/55 nozzles \\
$\mathrm{a}_{\mathrm{e}}=500 \mu \mathrm{m}$ & & Wi/92379 (OIFW
\end{tabular}

Fig. 8 Surface roughness Rz for different grain sizes and feeds

contact area temperatures and therefore to higher (tensile) residual stress, while the linear increase of the residual stress of the B602 tool is credited to constant material removal mechanisms at higher removal rates.

\subsection{Surface roughness}

As the presented tools are designed for roughing operations, the surface roughness is not a focus point of this paper. It is for future applications, however, important to present the resulting surface roughness when working with these tools. The surface roughness is proportional to the chip thickness which is in turn a function of the grain size. Coarser grains therefore lead to higher surface roughness. Figure 8 shows the surface roughness Rz for increasing feeds for both tools. On the left, the surface roughness of the soft shafts is shown, while the right diagram presents the roughness of the hardened shafts. It is apparent that the roughness after grinding with the B602 tool is about twice as high as the roughness after the use of $\mathrm{B} 252$ tools, measuring $\mathrm{Rz}=58 \mu \mathrm{m}$ for a feed of $\mathrm{f}=0.3 \mathrm{~mm}$ while the $\mathrm{B} 252$ grinding results in a roughness of $\mathrm{Rz}=31 \mu \mathrm{m}$. The roughness progressively increases with rising feeds for both tools to $\mathrm{Rz}=82 \mu \mathrm{m}$ (B602) and $\mathrm{Rz}=41 \mu \mathrm{m}$ (B252) for soft shafts. For hardened shafts, the roughness increases over a range of $35 \mu \mathrm{m} \leq \mathrm{Rz}<55 \mu \mathrm{m}$ (B602) and $20 \mu \mathrm{m} \leq \mathrm{Rz}<40 \mu \mathrm{m}$ (B252).

Summarizing, the aforementioned clogging of the B252 tool leads to smoother surfaces resulting from additional rubbing of the adhering material with the workpiece surface. The surface roughness of the hardened shafts is overall significantly lower than that of the soft shafts, as the material separation is more brittle and therefore fewer bulgings occur on both sides of a single grain engagement. 


\section{Conclusion and outlook}

Since CBN grains beyond grain sizes $d_{g}>300 \mu \mathrm{m}$ have only recently been introduced, there has been no research into their performance. This paper shows investigations of electroplated tools with B252 grains and coarse B602 grains regarding their suitability for roughing operations of soft and hardened $100 \mathrm{Cr} 6$ steel shafts under varying feeds. The process forces were measured during the investigations, wear behaviour, roughness and resulting residual stress were analysed. The following conclusions were drawn:

- The increasing grinding force ratio of the B602 tool indicates improving material removal efficiency for higher feeds, due to higher grain penetration of the workpiece which reduces friction between grain and workpiece

- The B602 tool shows constant material removal mechanisms proven by an linear increase of residual stress. Thus, its performance limit is not reached yet

- Process forces increase with higher feeds due to increased grain loads

- Larger grains lead to overall reduced process forces

- The clogging up of the B252 tool's chip space as a result of the high chip lengths limits its performance

- The clogged B252 tool induces exponentially increasing residual stress due to additional friction

- The B252 tool provides a lower surface roughness due to rubbing of the clogged surface on the workpiece

- To reduce the clogging of the B252 tool, the chip dimensions need to be altered by higher cutting speed or lower feeds

- Brittle material removal leads to lower surface roughnesses in hard grinding

- The coarse B602 tool is well suited for high productive roughing processes, while the $\mathrm{B} 252$ tool is unsuited for the investigated high performance process

Further investigations will focus on the increase of grain load to investigate the limits of these coarse B602 grains as there has not yet been any sign of grain wear. Additionally, improvements of the cooling conditions are being conducted especially by varying the nozzle types and monitoring pressure and flow rates to effectively cool and lubricate the contact area.

The used electroplated bond was well suited to retain the grains for all investigations and higher grain loads are possible. A key factor for the successful use of these tools is a deeper understanding into their chip formation and contact area temperatures. Investigations into this are currently conducted at the IFW.

Acknowledgements The authors thank the Federal Ministry for Economic Affairs and Energy (BMWi) Germany for their organizational and financial support within the project "Resource efficient and productive grinding with coarse CBN" (IGF-No. 20042 N/1).

Funding Open Access funding enabled and organized by Projekt DEAL.

Open Access This article is licensed under a Creative Commons Attribution 4.0 International License, which permits use, sharing, adaptation, distribution and reproduction in any medium or format, as long as you give appropriate credit to the original author(s) and the source, provide a link to the Creative Commons licence, and indicate if changes were made. The images or other third party material in this article are included in the article's Creative Commons licence, unless indicated otherwise in a credit line to the material. If material is not included in the article's Creative Commons licence and your intended use is not permitted by statutory regulation or exceeds the permitted use, you will need to obtain permission directly from the copyright holder. To view a copy of this licence, visit http://creativecommons.org/licenses/by/4.0/.

\section{References}

1. Klocke F (2009) Manufacturing processes 2: grinding, honing, lapping. Springer-Verlag, Berlin Heidelberg, Berlin, Heidelberg

2. Toenshoff HK, Denkena B (2013) Basics of cutting and abrasive processes. Springer, Berlin Heidelberg; Imprint; Springer, Berlin, Heidelberg

3. Klocke F, Barth S, Mattfeld P (2016) High performance grinding. CIRP Conf von High Performance Cutting 46:266-271

4. Tawakoli T, Barrett CG (eds) (1993) High efficiency deep grinding: technology, process planning, and economic application. Mechanical Engineering Publ, London

5. Batako ADL, Morgan MN, Rowe BW (2013) High efficiency deep grinding with very high removal rates. Int J Adv Manuf Technol 66(9-12):1367-1377. https://doi.org/10.1007/s00170-012-4414-7

6. Stephenson DJ, Jin T, Corbett J (2002) High efficiency deep grinding of a low alloy steel with plated CBN wheels. CIRP Ann 51(1):241-244. https://doi.org/10.1016/S0007-8506(07)61508-X

7. Morgan MN, Rowe WB, Batako A. Energy Limitations in HEDG and Conventional Grinding. KEM 2004; 257-258: 63-8 [https:// doi.org/https://doi.org/10.4028/www.scientific.net/KEM.257-258. 63]

8. Jin T, Stephenson DJ (2003) Investigation of the heat partitioning in high efficiency deep grinding. Int J Mach Tools Manuf 43(11):1129-1134. https://doi.org/10.1016/S0890-6955(03) 00123-8

9. Denkena B, Grove T, Göttsching T (2015) Grinding with patterned grinding wheels. CIRP J Manuf Sci Technol 8:12-21. https://doi.org/10.1016/j.cirpj.2014.10.005

10. Aurich JC, Herzenstiel P, Sudermann H, Magg T (2008) Highperformance dry grinding using a grinding wheel with a defined grain pattern. CIRP Ann 57(1):357-362. https://doi.org/10.1016/j. cirp.2008.03.093

11. Uhlmann E, Hochschild L (2013) Tool optimization for high speed grinding. Prod Eng Res Devel 7(2-3):185-193. https://doi.org/10. 1007/s11740-013-0447-5

12. Marschalkowski K, Biermann D, Weinert K (2012) On the characteristics of high-performance internal peel grinding using electroplated CBN wheels. Mach Sci Technol 16(4): 580-600 https:// doi.org/10.1080/10910344.2012.731950

13. Ichida Y, Fujimoto M, Inoue Y, Matsui K (2010) Development of a high performance vitrified grinding wheel using ultrafine-crystalline cBN abrasive grains. JAMDSM 4(5):1005-1014. https:// doi.org/10.1299/jamdsm.4.1005 
14. Tatzig L, Grove T, Denkena B (2019) Model of tool loads in dry diamond wire grinding of steel. Int J Adv Manuf Technol 102(58):2085-2093. https://doi.org/10.1007/s00170-018-03248-y

15. Denkena B, Grove T, Göttsching T. Noch schneller als Drehen. WB Werkstatt + Betrieb 2017; (3): 68-71.

16. Jin T, Stephenson DJ, Corbett J (2002) Burn threshold of highcarbon steel in high-efficiency deep grinding. Proc Inst Mech Eng Part B 216(3):357-364. https://doi.org/10.1243/0954405021 520021
Publisher's Note Springer Nature remains neutral with regard to jurisdictional claims in published maps and institutional affiliations. 